\title{
Technical Note CRYOFRABR\#002/2021: Activated-copper-coated alumina granules synthesis
}

Rosembergue G. L. Gonçalves ${ }^{1}$, Renato S. Junior, Pedro B. Neto, Roza Doubnik ${ }^{2}$, Mark Adamowski ${ }^{2}$, David Montanari ${ }^{2}$, Ana A. B. Machado ${ }^{3}$, Ettore Segreto ${ }^{3}$, Thiago P. M. Alegre ${ }^{3}$, Cris Adriano 3 , P. G. Pagliuso $^{3}$, Ivana Cruz ${ }^{4}$, Dilson Cardoso ${ }^{4}$, Cristhiane G. Maciel Reis ${ }^{5}$, José Mansur Assaf ${ }^{4}$, Elisabete Moreira Assaf ${ }^{1}$

1 University of São Paulo, São Carlos Institute of Chemistry, Brazil

2 Fermi National Accelerator Laboratory, Batavia, IL USA

3 Gleb Wataghin Physics Institute, University of Campinas, Campinas, SP, Brazil

4 Federal University of São Carlos, Chemical Engineering Department, Brazil

5 Federal University of São Joao Del Rey, Brazil

Detailed experimental studies of oxygen capture in the argon purification process using activated-copper on alumina and layered double hydroxide (LDH) were carried out, and the results were compared to the BASF commercial copper material $\mathrm{Cu}-0226 \mathrm{~S}$ performance. Here, we report the following main findings: i) the desired crystal structures for the studied materials were obtained after the synthesis process, ii) the use of the $\mathrm{LDH}$ structure promoted greater dispersion of the $\mathrm{CuO}$ phase when compared to BASF commercial catalyst, iii) alumina impregnated with copper demonstrated a similar result as the BASF sample for $\mathrm{O}_{2}$ capture, and iv) among the three samples evaluated, the LHD sample demonstrated the best results regarding oxygen capturing performance becoming a promising structure for further studies.

\section{INTRODUCTION}

This technical note is part of the studies proposed in the CRADA No. FRA-20160017 Annex B for purification media.

The synthesis method choice is fundamental to control the final properties of the media material, such as pore size, specific surface area, and interaction strength between support and active phase. Among the main methods of preparing diluted copper-based media candidate materials, wet methods are the most used, with emphasis on the methods of wet impregnation, coprecipitation, and sol-gel.

Thus, we propose the use of the impregnation of $\mathrm{Cu}$ on $\mathrm{Al}_{2} \mathrm{O}_{3}$ by the sol-gel method, using copper salt and poly (ethylene oxide) polymer (PEO) as a dispersing agent and co-precipitation of layered double hydroxide (LDH) as an intermediate structure (Figure 1) to increase the dispersion of the active phase $\mathrm{Cu}^{0}$. In this work, all catalysts have $10 \% \mathrm{w} / \mathrm{w}$ copper as nominal content. For comparison, BASF commercial copper material $(\mathrm{Cu}-0226 \mathrm{~S})$ is used as a reference.

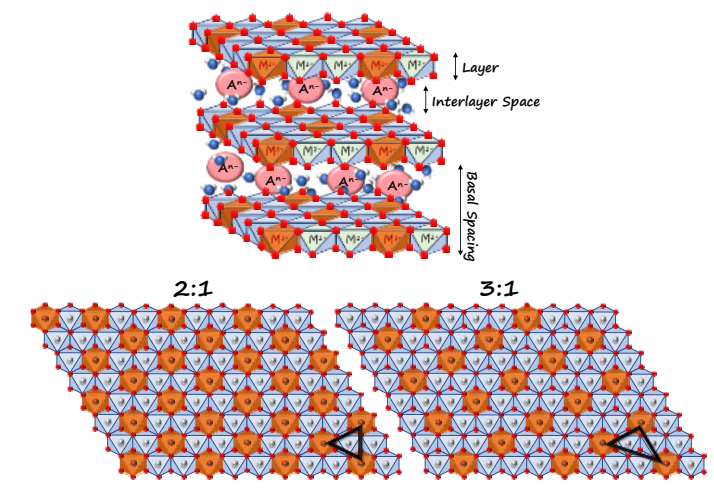

Figure 1: The idealized crystal structure of LDH with different $\mathrm{M}^{2+}: \mathrm{M}^{3+}$ molar.

\section{MATERIALS AND METHODS}

\section{(LDH) \\ LAYERED DOUBLE HYDROXIDE}

The LDH samples were prepared by a coprecipitation method at a constant $\mathrm{pH}$ value as follows: a solution containing $\mathrm{Cu}\left(\mathrm{NO}_{3}\right)_{2} 3 \mathrm{H}_{2} \mathrm{O}$ $(8.0 \mathrm{mmol}), \mathrm{Mg}(\mathrm{Cl})_{2} \quad 6 \mathrm{H}_{2} \mathrm{O}$ (84.3 mmol), and $\mathrm{Al}(\mathrm{Cl})_{3} 6 \mathrm{H}_{2} \mathrm{O}(30.8 \mathrm{mmol})$ in water $(250 \mathrm{~mL})$ was added dropwise under vigorous stirring to a solution containing $\mathrm{Na}_{2} \mathrm{CO}_{3}(90.0 \mathrm{mmol})$ in water $(1000 \mathrm{~mL})$. A NaOH solution $\left(2.0 \mathrm{~mol} \mathrm{~L}^{-1}\right)$ was added dropwise to keep the $\mathrm{pH}$ value constant at 10. After synthesis, the solid in suspension was 
washed with deionized water and dried at $70{ }^{\circ} \mathrm{C}$. To prepare the calcined LDH sample (CLDH), it was heated at $500{ }^{\circ} \mathrm{C}$ for $2 \mathrm{~h}$ under ambient atmosphere ${ }^{1}$.

\section{$\mathrm{CuAl}_{2} \mathrm{O}_{3}$ PEO}

Based on the work developed by Tokudome and collaborators ${ }^{2}$, a meso/macroporous alumina was prepared using $\mathrm{Al}(\mathrm{Cl})_{3} 6 \mathrm{H}_{2} \mathrm{O}$. In this synthesis PEO $\left(\mathrm{Mw}=100000 \mathrm{~g} \mathrm{~mol}^{-1}\right)$ and $\mathrm{Al}(\mathrm{Cl})_{3} 6 \mathrm{H}_{2} \mathrm{O}$ were dissolved in a mixture of deionized water and ethanol under stirring at room temperature. Then, propylene oxide (PO) was added to the system under agitation. The homogeneous sol formed after the PO addition was sealed at $40{ }^{\circ} \mathrm{C}$ for gelatinization and aging. Then they were dried and calcined at $700{ }^{\circ} \mathrm{C}$ in air. To perform the deposition, a solution containing the precursor $\left(\mathrm{Cu}\left(\mathrm{NO}_{3}\right)_{2} 3 \mathrm{H}_{2} \mathrm{O}\right)$ dissolved in water was used. Then, meso/macroporous $\mathrm{Al}_{2} \mathrm{O}_{3}$ was dispersed in water, and the two solutions were mixed under vigorous stirring, and then dried. The dry samples were calcined at $500{ }^{\circ} \mathrm{C}$ with a synthetic airflow to decompose the salt and promote the deposition of the active phase over the entire surface of the support.

\section{CHARACTERIZATION}

The X-ray powder diffraction (XRD) data were obtained using a Rigaku Multiflex diffractometer operated in the range $5^{\circ}<2 \theta<80^{\circ}$, with $\mathrm{Cu} \mathrm{K} \alpha$ radiation $(40 \mathrm{kV}, 30 \mathrm{~mA})$.

$\mathrm{N}_{2}$ adsorption/desorption isotherms were carried out in a Quantachrome NOVA 1000e volumetric adsorption analyzer at $-196{ }^{\circ} \mathrm{C}$. First, the samples were outgassed under vacuum at 200 ${ }^{\circ} \mathrm{C}$, and the $\mathrm{N}_{2}$ isotherm was obtained by successive steps of adsorption and desorption of this gas. The specific surface area was calculated by the Brunauer-Emmett-Teller (BET) method by using data of the adsorption branch of the isotherm in the relative pressure $\mathrm{P} / \mathrm{P}_{0}$ range of $0.05-0.2$. The pore size distribution was calculated by the Barrett-Joyner-Halenda (BJH) method.

Temperature-programmed reduction (TPR) analyses were performed in a Micromeritics Pulse ChemiSorb 2750 equipment. The hydrogen consumption was monitored by a thermal conductivity detector (TCD).

\section{REDUCTION/OXIDATION CYCLES}

Reproducibility tests of the materials in sequential reduction and oxidation cycles were performed. Samples with $100 \mathrm{mg}$ of the materials were placed in a U-shaped quartz tube reactor and reduced under $10 \% \mathrm{H}_{2} / \mathrm{Ar}(\mathrm{v} / \mathrm{v})$ mixture flowing at $25 \mathrm{~mL} \mathrm{~min}^{-1}$, from room temperature to $310^{\circ} \mathrm{C}$ at a heating rate of $10^{\circ} \mathrm{C} \mathrm{min}{ }^{-1}$. After the reduction, the sample oxidation was performed under a $5 \%$ $\mathrm{O}_{2} / \mathrm{Ar}(\mathrm{v} / \mathrm{v})$ mixture flowing at $20 \mathrm{~mL} \mathrm{~min}^{-1}$ for 30 min at room temperature and atmospheric pressure. Temperature Programmed Reduction (TPR) of the oxidized samples was performed to estimate the amount of copper oxidized. The hydrogen consumed (determined by the area under of TPR profile) was compared before and after the oxidation cycles for all studied samples.

\section{RESULTS}

In Figure 2, the XRD pattern of the LDH

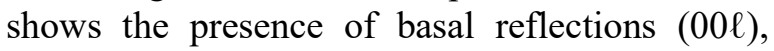
(003) e (006) ${ }^{3,4}$, which are related to the lamellar stacking plane characteristic of LDH structure. For this material, the interlayer space (d) calculated from the Bragg equation is roughly 7.7 $\AA^{1}$, which can be assigned to the intercalation of carbonate ions between the inorganic lamellae. The alumina XRD data (Figure $2 \mathrm{~B}$ ) presented diffraction peaks corresponding to poorly crystallized $\gamma-\mathrm{Al}_{2} \mathrm{O}_{3}\left(2 \theta=37,5^{\circ}, 45,9^{\circ}\right.$ e $67,0^{\circ}$

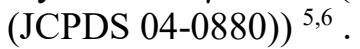
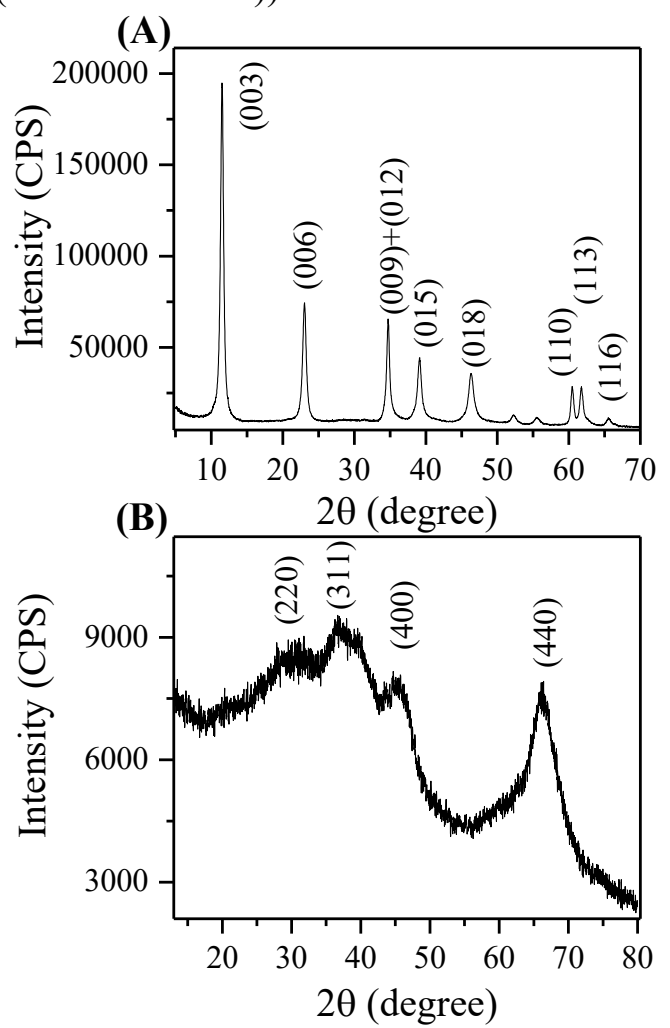

Figure 2: XRD patterns of (A) CuMgAl LDH and (B) $\mathrm{Al}_{2} \mathrm{O}_{3}$ PEO. 
For calcined samples, the XRD analysis (Figure 3) showed the collapse of the layered structure due to the disappearance of the basal reflections and the typical formation of the defect periclase $\quad \mathrm{MgO} \quad$ structure $\quad(\mathrm{Mg}(\mathrm{Al}) \mathrm{O})^{7}$. For $\mathrm{CuAl}_{2} \mathrm{O}_{3}$ PEO, can be observed that the addition of $10 \mathrm{wt} \%$ of copper did not cause any significant change in the diffraction patterns of the poorly crystallized $\gamma-\mathrm{Al}_{2} \mathrm{O}_{3}$. Furthermore, in the XRD of $\mathrm{CuO}$ BASF, one can see that in addition to the relative peaks of the $\gamma-\mathrm{Al}_{2} \mathrm{O}_{3}$ phase, two peaks correspond to the $\mathrm{CuO}$ crystalline structure what can indicate less dispersion of the $\mathrm{CuO}$ phase. Thus the absence of XRD peaks related to the formation of a crystalline $\mathrm{CuO}$ phase in the $\mathrm{CuMgAl} \mathrm{LDH}$ and $\mathrm{CuAl}_{2} \mathrm{O}_{3}$ PEO is a strong indication that the copper species were well dispersed on the support ${ }^{8}$.

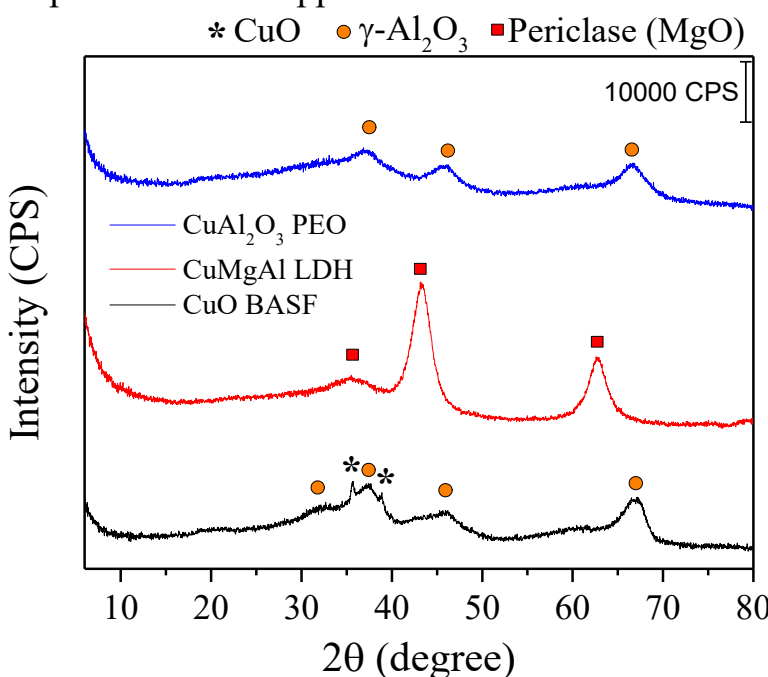

Figure 3: $\mathrm{XRD}$ patterns of $\mathrm{CuO} \mathrm{BASF}, \mathrm{CuMgAl}$ $\mathrm{LDH}$, and $\mathrm{CuAl}_{2} \mathrm{O}_{3}$ PEO.

The study of the textural properties of the samples is of great importance since the accessibility of the oxygen to the active sites $\left(\mathrm{Cu}^{0}\right)$ is directly related to the specific surface and the pore size. Figure 4 shows the $\mathrm{N}_{2}$ adsorption /desorption isotherms of the calcined samples. From these results, it is noted that the $\mathrm{Cu} \mathrm{BASF}$, $\mathrm{Al}_{2} \mathrm{O}_{3}$ PEO, and $\mathrm{CuAl}_{2} \mathrm{O}_{3}$ PEO samples have a similar shape in terms of the hysteresis loop between the adsorption/desorption branches, being classified as Type IV isotherms according to IUPAC, characteristic of mesoporous materials ${ }^{9}$. The $\mathrm{N}_{2}$ adsorption/desorption isotherms of CuMgAl LDH is type III, according to the IUPAC classification ${ }^{10}$, characterized by the absence of a plateau at relative pressure close to 1 , evidencing the presence of macropores.

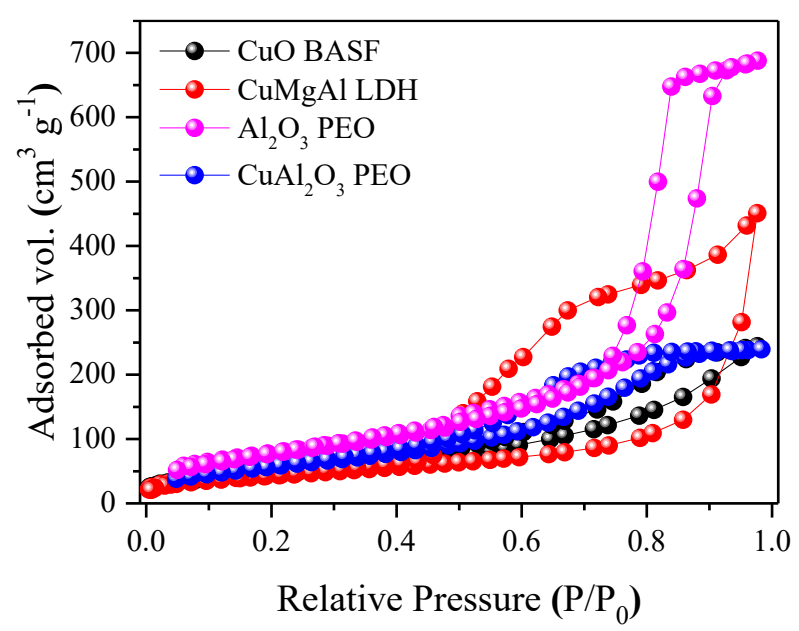

Figure 4: $\mathrm{N}_{2}$ adsorption/desorption isotherms of $\mathrm{CuO}$ BASF, CuMgAl LDH, $\mathrm{Al}_{2} \mathrm{O}_{3}$ PEO, and $\mathrm{CuAl}_{2} \mathrm{O}_{3} \mathrm{PEO}$.

Table 1 shows the values of the textural properties of the investigated materials. These results show that all $\mathrm{Cu}$-based samples have a close specific surface area and average pore sizes and that the addition of copper promoted a decrease in the surface area, pore size, and pore volume. The relative decrease in pore size and volume pore of the sample with the highest $\mathrm{Cu}$ content, relative to the bare support, was related to partial blockage of the pores, as well as the collapse of the thin mesopore walls during the processes of impregnation and calcination ${ }^{11}$.

Table 1: Surface area and porosity characteristics.

\begin{tabular}{crrc}
\hline Sample & $\begin{array}{c}\text { Specific } \\
\text { surface } \\
\left(\mathrm{m}^{2} \mathrm{~g}^{-1}\right)\end{array}$ & $\begin{array}{c}\text { Pore } \\
\text { volume } \\
\left(\mathrm{cm}^{3} \mathrm{~g}^{-1}\right)\end{array}$ & $\begin{array}{c}\text { Average } \\
\text { pore size } \\
(\mathrm{nm})\end{array}$ \\
\hline $\mathrm{CuO} \mathrm{BASF}$ & 166 & 0.39 & 3.5 \\
$\mathrm{CuMgAl} \mathrm{LDH}$ & 152 & 0.92 & 3.8 \\
$\mathrm{Al}_{2} \mathrm{O}_{3} \mathrm{PEO}$ & 286 & 1.12 & 10 \\
$\mathrm{CuAl}_{2} \mathrm{O}_{3} \mathrm{PEO}$ & 200 & 0.38 & 5.4 \\
\hline
\end{tabular}

To evaluate the $\mathrm{O}_{2}$ capture capacity through the oxidation of the $\mathrm{Cu}^{0}$ species $\left(2 \mathrm{Cu}^{0}+\mathrm{O}_{2} \rightarrow\right.$ $2 \mathrm{CuO}$ ), fresh samples were first reduced from 30 $-310{ }^{\circ} \mathrm{C}$ under $10 \% \mathrm{H}_{2} / \mathrm{Ar}(\mathrm{v} / \mathrm{v})$ mixture. Then, the furnace was cooled to $30^{\circ} \mathrm{C}$ to perform the oxidation process under the $5 \% \quad \mathrm{O}_{2} / \mathrm{Ar}(\mathrm{v} / \mathrm{v})$ mixture for $30 \mathrm{~min}$. After the oxidation process, a new reduction step $\left(\mathrm{CuO}+\mathrm{H}_{2} \rightarrow \mathrm{Cu}^{0}+\mathrm{H}_{2} \mathrm{O}\right)$ was performed to determine the amount of copper oxidized in relation to the fresh sample.

Figure 5 shows the \% ratio between the area under the TPR profile of the sample after oxidation by the area under the TPR profile of the fresh sample. For this result, it is observed that 
after 3 oxidation cycles no deactivation occurs in any sample.

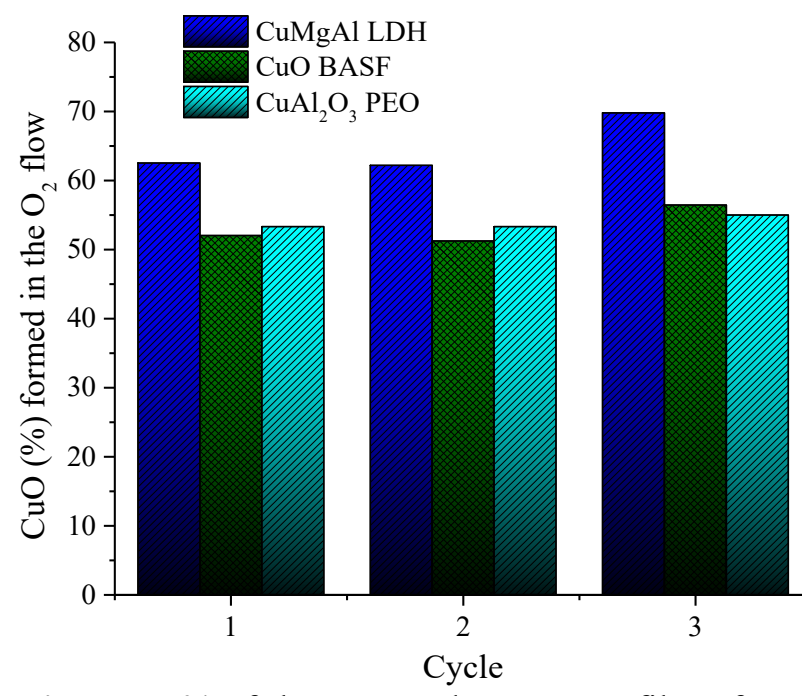

Figure 5. $\%$ of the area under TPR profiles after the oxidation cycle ((area after/area before) $* 100)$.

Besides, it is shown in figure 5 that the sample impregnated with copper prepared in the laboratory $\left(\mathrm{CuAl}_{2} \mathrm{O}_{3} \mathrm{PEO}\right)$ has equivalent results to that commercial sample the BASF, in terms of $\mathrm{O}_{2}$ capture efficiency, and that the CuMgAl LDH has the highest $\mathrm{O}_{2}$ capture capacity. This enhanced performance found for LDH can be explained by the probable better dispersion of the $\mathrm{Cu}^{0}$ particles between the two compared materials here since the dispersion of the LDH copper occurs at an atomic level in layers ${ }^{3,11}$.

\section{CONCLUSION}

The results obtained so far by this work show that the $\mathrm{CuMgAl} \mathrm{LDH}$ and $\mathrm{CuAl}_{2} \mathrm{O}_{3}$ PEO samples prepared by our research group have excellent structural characteristics such as good dispersion of the $\mathrm{CuO}$ phase, high porosity, and high $\mathrm{O}_{2}$ capture capacity. By comparison with the commercial $\mathrm{CuO} \mathrm{BASF}$, it was observed that the sample $\mathrm{CuAl}_{2} \mathrm{O}_{3}$ PEO presented similar results regarding the capture of $\mathrm{O}_{2}$ and that the $\mathrm{CuMgAl}$ LDH sample has the highest $\mathrm{O}_{2}$ capture capacity among these evaluated materials.

\section{ACKNOWLEDGEMENT}

This work was supported by São Paulo Research Foundation (FAPESP) - Grant \# 2020/01609-2.

\section{REFERENCES}

1. Santos, R. M. M. dos et al. Adsorption of Acid Yellow 42 dye on calcined layered double hydroxide: Effect of time, concentration, $\mathrm{pH}$ and temperature. Appl. Clay Sci. 140, 132-139 (2017).

2. Tokudome, Y., Fujita, K., Nakanishi, K., Miura, K. \& Hirao, K. Synthesis of monolithic $\mathrm{Al} 2 \mathrm{O} 3$ with well-defined macropores and mesostructured skeletons via the sol-gel process accompanied by phase separation. Chem. Mater. 19, 3393-3398 (2007).

3. Guo, X., Zhang, F., Evans, D. G. \& Duan, X. Layered double hydroxide films: synthesis, properties, and applications. Chem. Commun. 46, 5197 (2010).

4. José Dos Reis, M., Silvério, F., Tronto, J. \& Valim, J. B. Effects of $\mathrm{pH}$, temperature, and ionic strength on adsorption of sodium dodecylbenzene sulfonate into $\mathrm{Mg}-\mathrm{Al}-\mathrm{CO} 3$ layered double hydroxides. J. Phys. Chem. Solids 65, 487-492 (2004).

5. Li, D. et al. NiAl2O4 Spinel Supported Pt Catalyst: High Performance and Origin in Aqueous-Phase Reforming of Methanol. ACS Catal. 9, 9671-9682 (2019).

6. Jung, Y. S., Yoon, W. L., Rhee, Y. W. \& Seo, $\mathrm{Y}$. S. The surfactant-assisted $\mathrm{Ni}-\mathrm{Al} 2 \mathrm{O} 3$ catalyst prepared by a homogeneous precipitation method for $\mathrm{CH} 4$ steam reforming. Int. J. Hydrogen Energy 37, 9340-9350 (2012).

7. Thomas, G. S., Radha, A. V., Kamath, P. V. \& Kannan, S. Thermally-induced polytype transformations among the Layered Double Hydroxides (LDHs) of Mg Zn with Al. $J$. Phys. Chem. B 110, 12365-12371 (2006).

8. Cassinelli, W. H. et al. Correlation between Structural and Catalytic Properties of Copper Supported on Porous Alumina for the Ethanol Dehydrogenation Reaction. ChemCatChem 7, 1668-1677 (2015).

9. IUPAC. Recommendations for the characterization of porous solids (Technical Report). Pure Appl. Chem. 66, 1739-1758 (1994).

10. Rouquerol, F., Rouquerol, J. \& Sing, K. S. W. Adsorption by Powders and Porous Solids: Principles, Methodology, and Applications. Academic Press (1999). doi:10.1016/B978012598920-6/50000-2.

11. Ye, R. P. et al. Recent progress in improving the stability of copper-based catalysts for 
hydrogenation of carbon-oxygen bonds.

Catal. Sci. Technol. 8, 3428-3449 (2018). 